\title{
HOW INTERNATIONAL STUDENTS IN CHINESE MEDICAL SCHOOLS PERCEIVE DISTANT LEARNING DURING THE COVID-19 PANDEMIC
}

\author{
Mohammed Al-Gerafi, Wenlan Zhang \\ School of Education, Shaanxi Normal University, Xi'an, China \\ malgerafi@gmail.com, wenlan19@163.com
}

\begin{abstract}
Purpose: The aim of this study is to assess the perception of international medical students of e-learning in China, since medical teaching during the COVID-19 pandemic had to adapt to challenges, and students had to cope with the new teaching modality, more so international students. Therefore, the opinion of students with their first contact to a fully virtual education will be helpful to modify e-teaching to better suit the students' needs. Method: Four hundred seven medical students, in China, were recruited via social media and were asked to complete structured questionnaires, regarding technical and content aspects of their e-courses. Findings: Most issues reported were of technical nature, especially for students attending the school distantly and network instability/unavailability was frequently $(52.48 \%)$. Moreover, the audio was less helpful than texts/images and the senior students were less satisfied with the technical $(0.005)$ and content $(\mathrm{p}=0.001)$ aspects. They also were more critical of their teachers' performance $(\mathrm{p}=0.042)$. Clinical cases and scenarios also received the lowest score. Implications for research and practice: Overall students did not feel confident with the e-learning, comfortable implementing it to patients and were reluctant to embrace it. Both technical difficulties and understanding issues impeded international students from embracing e-learning medical teaching, in China and efforts need to be made to acclimatise them to this new reality.
\end{abstract}

Keywords: electronic learning; Distance Electronic Learning; e-courses; virtual medical teaching; medical students; International students.

\section{Introduction}

During the past years, the number of international students have constantly been increasing and student mobility is going to be the main trend for the years to come. The most obvious reasons are the globalisation of the economy, which allows unhindered travelling, and the increase of the internet, which shows opportunities to youngsters away from their own country. The growing attention given to international students is reflected in the interest of international organisations, such as OECD (Organisation for Economic Co-operation and Development), UNESCO (United Nations Educational, Scientific and Cultural Organisation), and IIE (Institute of International Education) that have started data collection and provide statistics on the international student mobility (ISM) (OECD, 2020; UNESCO UIS, 2020). Additionally, many national organisations have started monitoring the inward and outward movement of their student population (Ministry of Education of the People's Republic of China, 2019). On the other hand, international merit rankings for universities, nowadays, include the number of international recruitments as an important indicator of their quality (Sheeja et al., 2018).

Many countries seek to attract the best and the brightest students on a global scale, either by waving their fees as a scholarship or by providing work permits at the end of their studies. Other countries encourage student mobility within their jurisdiction, as part of their unification process, such as the European Union with the ERASMUS programme (Restaino et al., 2020). The target is to attract the best and nurture them in the national culture, in order to integrate them into the regional workforce; finally; learning the local language is the first step for this integration. China is one of those countries that seek to attract international talents, within an ongoing active recruitment programme. In 1992, China had only 14,000 international students, while by 2017, it was the third ISM country, just behind the USA and UK, and in 2018 there were a total of 492,185 international students from 196 countries in China's higher education institutes, an increase of $0.62 \%$ from just the previous year (Yang, 2020).

COVID-19 pandemic that hit the world hard and abruptly, halted free mobility of people worldwide, students' included. Some students found themselves stranded in a foreign country, while others were at home, away from the universities. As travel restrictions were applied and most communications went online, so did university teaching. E-learning (EL), or Distant e-learning (DEL) or virtual reality (VR) learning (Choules, 2007), is not a new concept. Specialised platforms (E.g., Coursera, EdX, etc.), have had a long history of linking academic knowledge with the wider public. However, they usually teach theoretical subjects, and it is exceedingly difficult to grasp e-courses about hands-on disciplines. Given the pandemic, though, the transition to virtual classes is imperative. In this context, medical studies have been difficult to

(C) Mohammed A. M. ALGerafi, Wenlan Zhang. 2021. Published by Igor Sikorsky Kyiv Polytechnic Institute. This is an Open Access article distributed under the terms of the licence CC BY 4.0 
transition to e-learning, especially during the clinical years, and many studies have been undertaken to study the implementation of different approaches, so that improvements can be made, and better methodologies can be generated (Sandhu \& de Wolf, 2020).

On top of the difficult implementation of e-learning, in the medical field, as far as content and structure are concerned, international students face additional difficulties that pertain to the technical aspect, when trying to study from afar, or in a non-native language. The additional level of complexity is the main theme of the present research.

Therefore, in this study, we polled international students who have enrolled in medical schools in China and during the pandemic lived either in China or back in their home countries. We investigated the content aspect that pertains to all e-courses, the technical aspect of studying from afar, and the general attitude of students towards the e-learning experience. The compilation of these findings provides an additional layer of knowledge to the e-learning experience during the COVID-19 pandemic.

\section{Methods}

This is a prospective cross-sectional study based on online questionnaires distributed during the recent COVID-19 pandemic lockdown in China (Spring semester March - August 2020), when all medical schools of the country switched to e-learning (EL). Medical studies in China last five years plus one year of clinical internship. Clinical specialisation usually involves a master's degree lasting two to three years.

Our target population comprised international students at Medical Schools, in China, including MBBS (Bachelor of Medicine and Bachelor of Surgery), Dentistry, and Pharmacology. International students in Chinese Medical Schools are estimated to be around 40,000. In order to assure a representative sample of the international medical students in our study, we calculated a minimum of 381 correctly completed questionnaires, as previously described (Cardinale et al., 2011).

The researchers designed the questionnaire and distributed them in a demo format, to 30 students. We rephrased questions with the highest rate of error to make them more comprehensive and then distributed them to a wider audience. The validated questionnaire was posted, for four weeks, on the WeChat platform that is widely used by all medical students countrywide. It was also published in the university groups of each university by medical students and the snowball sampling method was used to reach the largest number of respondents and increase participation. The survey ended when the predesignated number was reached.

The questionnaire consisted of four main domains. The first one comprised of the demographics of the participants, namely, age, gender, country of origin, country of residence. It also included students' previous DEL experiences where candidates were asked to rate their experiences using a four-point scale "None, Little, Adequate or Substantial". They also provided the name of the application they previously have used.

The second domain was about the technical component of the e-learning course. A list of applications used during the lockdown was provided to students, but they also had the capacity to add more. The assessment was done on the connectivity and the user-friendliness of the e-learning applications. Videos, images, and sound were also evaluated, on their clarity and quality.

The third domain was about the content and the structure of the e-lectures. They were asked if the information provided in the course were easily understood and comprehensive. The clinical aspects were also included in the statements, when applicable.

The fourth domain assessed students' attitudes towards the e-learning experience. They assessed the overall quality and value of e-learning, as well as the possibility of replacing live/traditional teaching or integrating it into the future curriculum. Lastly, they were asked to evaluate their teachers' performance during those e-courses.

Domains 2, 3, and 4 were all formulated in positively phrased statements and assessed in a five-point Likert scale (Strongly Disagree, Disagree, Neutral, Agree, Strongly Agree). Therefore, a total score for each domain was calculated as the sum of the individual statement. Data analysis was performed using Jamovi 1.27 statistical software.

\section{Results}

Four hundred twelve students completed the questionnaire, and five were excluded because they fell outside the pre-set parameters (e.g., they were taking only language classes, or were studying in non-medical disciplines). Therefore, the following data represent 407 students, aged 18-43 (mean 26.5 \pm 5.01 ); males were $248(63.39 \%)$, females $159(36.61 \%)$. These represent $0.6 \%$ (407/68000) of the total body of international medical students in China ( $\mathrm{Li} \&$ Sun, 2019), thus a representative sample of the target population (confidence level 5\%). The response rate was $100 \%$, as there was a rigorous follow-up when incomplete questionnaires were received and clarifications were asked, to ensure a precise depiction of the situation. 
Table 1. Demographic data of participants

\begin{tabular}{|c|c|c|}
\hline Type of application & No & $\%$ \\
\hline Gender & 407 & \\
\hline Male & 248 & 63.39 \\
\hline Female & 159 & 36.61 \\
\hline Continent of Origin & 407 & \\
\hline Asia & 286 & 70.27 \\
\hline Africa & 101 & 24.82 \\
\hline Europe & 10 & 2.46 \\
\hline America & 7 & 1.72 \\
\hline Oceania & 3 & 0.74 \\
\hline Place of Residence* & 407 & \\
\hline China & 226 & 55.61 \\
\hline Outside China & 181 & 44.39 \\
\hline
\end{tabular}

* place of residence during the e-learning period

They originated from all continents, but understandably most come from Asia (70.27\%) and then Africa (24.82\%) (Table 1). This trend coincides with the distribution of students from the official data (Asian students 59.95\% and African students $16.57 \%$ ), though not the exact numbers (Ministry of Education of the People's Republic of China, 2019). Nevertheless, almost half of the students (55.61\%) were residing in China during the pandemic, while the rest $(44.39 \%)$ returned to their home countries.

Table 2. Educational data on participants

\begin{tabular}{|l|l|l|}
\hline & No & \% \\
\hline Year in medical school* & 158 & \\
\hline non-clinical years (1-3) & 91 & 57.59 \\
\hline clinical years (4-6) & 59 & 37.34 \\
\hline Department of Studies & 407 & \\
\hline MBBS & 335 & 82.31 \\
\hline Dentistry & 40 & 9.83 \\
\hline Pharmacology & 32 & 7.86 \\
\hline Educational Level & 407 & \\
\hline Bachelor & 158 & 38.82 \\
\hline Master** & 175 & 43.00 \\
\hline PhD & 74 & 18.18 \\
\hline Previous e-learning experience & 407 & \\
\hline None & 289 & 71.01 \\
\hline Little & 34 & 8.35 \\
\hline Adequate & 61 & 14.99 \\
\hline Substantial & 23 & 5.65 \\
\hline
\end{tabular}

* applies to Bachelor students only $(\mathrm{N}=158)$; Master's degree involves Clinical Specialisation

The majority of students were enrolled in MBBS (335/407, 82.31\%) while some were in Dentistry (40/407, 9.83\%) and in Pharmacology (32/407, 7.86\%). Almost one-third of participants were at a Bachelor level (158/407, 38.82\%), while the majority at a Master's (175/407, 43\%) and fewer students pursuing a $\mathrm{PhD}$ $(74 / 407,18.18 \%)$. We have to remind that specialisation students are under the Master's group (Table 2).

Our data showed that $71.01 \%$ (289/407) of the responders had none, 38.6\% (34/407) little, $11.4 \%$ (61/407) adequate and 5.65\% (23/407) had substantial previous EL experience (Table 2). Their previous experience involved mainly DingTalk, Tencent, Google Apps, WeChat, Zoom, Skype Superstar, ZhiDao. In the present situation, the applications used were: DingTalk $(51.84 \%)$, Tencent meeting (48.65\%), Rain (43.49\%), Tencent QQ (36.61\%), MyMooc (37.35\%), YouTube Videos (36.12\%), Google Classroom (33.42\%), WeChat (32.43\%), Moodle E-learning (31.45\%), Zoom (18.18\%), Slides \& Voice (17.20\%), Superstar SMTOWN (11.3\%), and iSpace (7.62\%). Obviously, students used more than one application, and the percentages reflect their popularity in China. 
Table 3. Reason for missing class

\begin{tabular}{|l|l|l|}
\hline & No & \% \\
\hline Not missed class at all & 64 & 15.72 \\
\hline Missed class at least one & 343 & 84.28 \\
\hline Technical difficulties & 180 & $52.48^{*}$ \\
\hline Difficulty to understand & 60 & $17.49^{*}$ \\
\hline Uninterested & 39 & $11.37^{*}$ \\
\hline Time Difference & 34 & $9.91^{*}$ \\
\hline Sickness & 9 & $2.21^{*}$ \\
\hline Other reason & 21 & $6.12^{*}$ \\
\hline
\end{tabular}

*percentages apply to missed classes only $(\mathrm{N}=343)$

The students took $3.4 \pm 1.99$ courses per semester with a mean participation of 9.68 hours /week. Out of the total number of courses they took; $1.46 \pm 2.32$ were hands-on courses. Attendance was quite high, as they missed, on average, $3.69 \pm 3.12$ classes per semester. When asked about the reason they missed class, the majority $(52.48 \%)$ reported some technical difficulty. Other reasons included sickness $(2.21 \%)$, indifference $(11.37 \%)$, or difficulty to understand $(17.49 \%)$. Out of those who reported technical difficulties, $16.61 \%$ also reported difficulty in understanding because of the technical difficulty (Table 3). Both sexes took the same number of courses (M: 3.39; F: 3.40, $\mathrm{p}=0.948)$ but males took more hands-on courses (M: 1.67; F: 1.15, $\mathrm{p}=0.037$ ) and also missed more courses (M: 3.87; F: 3.41, $\mathrm{p}=0.080)$ per semester. (Table 4).

Table 4. E-learning data on participants by sex

\begin{tabular}{|l|l|l|l|}
\hline & Mean & SD & $\begin{array}{l}\text { p } \\
\text { (t-test) }\end{array}$ \\
\hline $\begin{array}{l}\text { No of e-courses/ during the } \\
\text { pandemic }\end{array}$ & & & \\
\hline Males & 3.39 & 1.99 & 0.948 \\
\hline Females & 3.40 & 2.00 & \\
\hline No of hands-on courses/semester & & & \multirow{2}{*}{$0.037^{*}$} \\
\hline Males & 1.67 & 2.51 & \\
\hline Females & 1.15 & 1.97 & 0.948 \\
\hline Average hours of e-learning/ week & & & \\
\hline Males & 9.67 & 4.92 & \multirow{2}{*}{0.080} \\
\hline Females & 9.69 & 4.90 & \\
\hline $\begin{array}{l}\text { How many times have you missed an } \\
\text { online course? }\end{array}$ & & & 3.08 \\
\hline Males & 3.87 & 3.16 & \\
\hline Females & 3.41 & & \\
\hline
\end{tabular}

$95 \%$ Confidence Interval, $*$ Statistically significant

Focusing on the technical difficulties encountered (regardless of whether they missed class or not because of it), the main reported problems fell into the following categories: network problem $(217 / 331$, $65.56 \%)$; general technical issues $(58 / 331,17.52 \%)$; application fault $(48 / 331,14.50 \%)$; (other cause $(8 / 331$, $2.42 \%)$; while $76(18.67 \%$ ) did not report any technical issues (data not shown). Obviously, most issues had to do with the network, either it did not work at all or was too slow to connect. It is noteworthy to point out that some of the general technical issues $(19 / 58,32.76 \%)$ had to do with the forbiddance of that application by the home country's regulations. In general, students who lived outside China reported more incidences of technical problems $(\mathrm{p}<0.001)$. The greatest technical difficulty for non-China-dwelling students was network instability $(\mathrm{p}=0.015)$; some students even reported electricity shortage. The answers pertaining to the technical aspect of e-learning are presented in detail in the Appendix (Tables S1 and S4). The answers suggest that most issues revolved around the quality of audio that was not as satisfactory as expected. Images and texts received the most praise, maybe because they are optical material, independent of auditory assistance. 
In terms of the subject content, it is important to note that students disagreed most with the statements that courses were adequately covering the subject (38.57\%), that they were enough for clinically oriented discussions (39.56\%), and that the case studies and scenarios were enough to gain clarity on the issue (39.07\%). This means that students felt it was not enough to cover all their questions, especially on clinical subjects and problems. The detailed answers are presented in the Appendix (Tables S2 and S4). In general, there was a bigger disagreement with the positive statements on the content portion than on the technical one.

As far as the general attitude of the participants is concerned, students were generally more negative, especially on the statements about implementing their knowledge on actual patients. They were less confident $(41.77 \%)$, less comfortable $(39.80 \%)$, and overall did not feel it was a beneficial experience (39.80\%). The detailed answers are presented in the Appendix (Tables S3 and S4).

Table 5. E-learning parameters according to the year of study (early $\leq 3$ vs advanced $>3$ years)

\begin{tabular}{|c|c|c|c|}
\hline & Mean & SD & $\begin{array}{l}\mathbf{p} \\
\text { (Spearman's rho) }\end{array}$ \\
\hline \multicolumn{4}{|c|}{ Missed e-courses } \\
\hline early $\leq 3$ & 3.50 & 2.88 & \multirow{2}{*}{$<0.001 * * *$} \\
\hline advanced $>3$ & 4.47 & 3.86 & \\
\hline \multicolumn{4}{|c|}{ Technical score } \\
\hline early $\leq 3$ & 18.5 & 4.12 & \multirow{2}{*}{$0.005^{* *}$} \\
\hline advanced $>3$ & 18.1 & 4.95 & \\
\hline \multicolumn{4}{|l|}{ Content score } \\
\hline early $\leq 3$ & 27.3 & 6.13 & \multirow{2}{*}{$0.001 * *$} \\
\hline advanced $>3$ & 26.6 & 8.24 & \\
\hline \multicolumn{4}{|l|}{ Attitude score } \\
\hline early $\leq 3$ & 29.7 & 6.56 & \multirow{2}{*}{$<0.001 * * *$} \\
\hline advanced $>3$ & 29.1 & 8.74 & \\
\hline \multicolumn{4}{|c|}{ Professors rose to the challenge } \\
\hline early $\leq 3$ & 3.19 & & \multirow{2}{*}{$0.042 *$} \\
\hline advanced $>3$ & 3.10 & & \\
\hline
\end{tabular}

$95 \%$ Confidence Interval, $* * *, * * *$ Statistically significant

The perception of students towards the e-courses largely depends on their educational stage; namely, senior students ( $>3$ years of studies) are more critical and negative than newer students Table 5 presents the detailed perception of various topics reflecting the respective score.

\section{Discussion}

This report presents a comprehensive overview of the problems, perceptions, and attitudes of international medical students in China during the current COVID-19 pandemic. Our results show that there are three distinct and almost equal groups of negatively, neutrally, and positively disposed students of approximately $30 \%$. This disposition seems to be reflected in all statements throughout the questionnaire. The differentiation, though, on individual answers points to the problematic areas of e-learning that merit further discussion.

International students are a vibrant, ever-growing group of people that choose to pursue, mostly tertiary, education abroad. Usually, the choice of country to study relies both on realistic factors (such as vicinity, tuitions, ease of access, etc.) as well as prospective factors such as (quality of education, power of the degree, perspectives to assimilate to the community, etc.) (Börjesson, 2017). Within these parameters, China is the most attractive epicentre for the east and possesses the third larger international community worldwide (Wen $\& \mathrm{Hu}, 2019$; Yang, 2020). A recent study showed the changing pattern of educational emigration during the pandemic (Mok et al., 2021). Therefore, the views of these international medical students in China during the pandemic are important, not only because of the sheer volume of students but as the trendsetter of international education (Hou \& Du, 2020).

The impact of the pandemic on medical students, especially, has been under a lot of investigation; firstly because, in most countries, students were banned from hospitals for safety reasons and secondly because it is 
a rather hands-on discipline and e-learning is exceedingly difficult to achieve through virtual reality. Virtual medical tools have been developed before the pandemic to assist medical students in familiarising themselves with the human body before actually performing any kind of procedure on it (Broudo \& Walsh, 2002). However, the transition to fully virtual teaching has been hard, and several weaknesses, such as technical challenges, confidentiality issues, reduced student engagement, and loss of assessments, have been reported (Wilcha, 2020). Moreover, the mental well-being of students has been impacted, though the repercussions are yet to be fully discovered. Additionally, the inequalities to accessing virtual teaching services worldwide were also uncovered during this health crisis (Qazi et al., 2020). This was obvious in our study since students attending classes from overseas were experiencing more difficulties connecting and missed more classes because of it. Network stability and network constraints on top of application failures impeded students from accessing class, as per our findings.

In our study, one initial observation is that most students are rather inexperienced in e-learning and did not take any e-courses in the past. Those who had previous experience were familiar with the platforms they used during the pandemic. The inexperience of students in e-courses has been investigated extensively during the pandemic lockdowns, across the globe, and has contributed to the negative experience recorded in most studies of this period. Therefore, the introduction of e-courses, webinars, and similar online modalities as a routine part of the medical curriculum could acclimatise students to this method of learning and make studying more flexible and adaptable to future adversities.

Moreover, studying is particularly important to medicals students, and maintaining a steady schedule is crucial to their success, with top students studying 6-8h/day in the preclinical stage (Liles et al., 2018). In our study, almost one-third of the participants admitted that their commitment levels dropped, and they studied less during virtual teaching. They also missed classes, though the percentages were rather low and mostly beyond their power. This showed a rather committed group of students that desired to keep a grip on their studies, despite the adverse outer circumstances. However, they did not feel confident and comfortable with the knowledge they acquired, should they be called to practice it on real patients. This points to the gap between theoretical knowledge and the practical use of that knowledge.

Medicine is more than diagnosing disease and prescribing a cure. The interpersonal relationship of the doctor-patient is built through mutual trust and understanding. These communicational skills are often passed to young doctors through observation of the elder colleagues/teachers within the actual setting (Liles et al., 2018). It is extremely hard to pass these soft skills electronically, and the felt detachment from the patient was especially evident to the senior students, who, in our study, were more critical and negative to elearning. Given the young age of all participants, there is no age gap or fear of technology to account for the discrepancy. It is rather due to the fact that senior students have already experienced the benefits of in-person teaching and frown upon the faceless e-teaching. Moreover, they acknowledge the multidimensionality of medicine as a vocation that moves further from reciting symptoms.

Overall, our participants scored lower on the technical aspect of e-learning than on the content itself, providing clues for improvement the technical aspect of e-learning, rather than the content. . On the same note, the audio component scored lower, either because of the aforementioned technical problems or because the teaching was in a foreign language, and the audio did not help in grasping the content. In this context, texts and images were more helpful. A recent study on improving medical teaching in China has listed 12 points that can help the online e-learning experience (Jiang et al., 2021). This means that the main problem lies in the country's telecommunication infrastructure, a domain beyond the capabilities of the Universities themselves. Moreover, new digital collaborating avenues that communicate more efficiently between countries should be developed. The pandemic has stretched the notion that the globe is nowadays unified and digital services should reflect it, regardless of the economic status of each individual country.

\section{Limitations}

The main limitation of our study lies in the methodology of questionnaire recruitment. Given that we used social media and a snowball sampling, the recruitment was not random, therefore any attempt to apply the findings to the general medical students' population may not be possible. Since the focus of this work were international students, it would also be valuable to have a comparison with the opinion of local students on the same topics, to better understand which areas apply to international students only.

We also have to pinpoint that the questionnaires were distributed at the beginning of the pandemic when e-learning was a novelty for both the students and the professors. It would be interesting to evaluate the opinions one year later when everybody had to adapt to the e-learning reality. 


\section{Conclusions}

The pandemic has changed not only the numbers of students moving but also the demographics. While pessimists predict that the pandemic will signal the end of the internationalisation of higher education, the issue is more complex and warrants further investigation. Universities, on the other hand, should make international studies more flexible and adjustable to the surrounding conditions. Moreover, it is believed that, beyond COVID-19, online teaching methods will be incorporated within the traditional medical curricula and a shift to virtual consultations over the traditional in-person medical practice. Therefore, the new generation of students should be trained to handle digital technology more efficiently because it seems that digitalisation has come to stay in our lives.

\section{Acknowledgements}

we acknowledge all medical school students in China for their participation. We also thank Dr. Mueataz A. Mahyoub with his team for helping us collect data.

References:

Australian, G. (2020). China's education arrangements during COVID-19 pandemic period. https://internationaleducation.gov.au/international-network/china/PolicyUpdates-China/Pages/China's-educationarrangements-during-COVID-19-pandemic-period.asp

Börjesson, M. (2017). The global space of international students in 2010. Journal of Ethnic and Migration Studies, 43(8), 12561275. https://doi.org/10.1080/1369183X.2017.1300228

Broudo, M., \& Walsh, C. (2002). MEDICOL: Online learning in medicine and dentistry. Academic Medicine: Journal of the Association of American Medical Colleges, 77(9), 926-927. https://doi.org/10.1097/00001888-200209000-00028

Cardinale, M., Newton, R., \& Nosaka, K. (2011). Strength and Conditioning. Wiley-Blackwell.

Choules, A. P. (2007). The use of elearning in medical education: A review of the current situation. Postgraduate Medical Journal, 83(978), 212-216. https://doi.org/10.1136/pgmj.2006.054189

Hou, C., \& Du, D. (2020). The changing patterns of international student mobility: A network perspective. Journal of Ethnic and Migration Studies, O(0), 1-25. https://doi.org/10.1080/1369183X.2020.1797476

Jiang, Z., Wu, H., Cheng, H., Wang, W., Xie, A., \& Fitzgerald, S. R. (2021). Twelve tips for teaching medical students online under COVID-19. Medical Education Online, 26(1), 1854066. https://doi.org/10.1080/10872981.2020.1854066

Li, W., \& Sun, H. (2019). Migration intentions of Asian and African medical students educated in China: A cross-sectional study. Human Resources for Health, 17(1), 88. https://doi.org/10.1186/s12960-019-0431-z

Liles, J., Vuk, J., \& Tariq, S. (2018). Study Habits of Medical Students: An Analysis of which Study Habits Most Contribute to Success in the Preclinical Years. MedEdPublish, 7. https://doi.org/10.15694/mep.2018.0000061.1

Ministry of Education of the People's Republic of China. (2019). Statistical report on international students in China for 2018. http://en.moe.gov.cn/news/press_releases/201904/t20190418_378586.html

Mok, K. H., Xiong, W., Ke, G., \& Cheung, J. O. W. (2021). Impact of COVID-19 pandemic on international higher education and student mobility: Student perspectives from mainland China and Hong Kong. International Journal of Educational Research, 105, 101718. https://doi.org/10.1016/j.ijer.2020.101718

OECD. (2020). Students-International student mobility. https://data.oecd.org/students/international-student-mobility.htm

Qazi, A., Naseer, K., Qazi, J., AlSalman, H., Naseem, U., Yang, S., Hardaker, G., \& Gumaei, A. (2020). Conventional to online education during COVID-19 pandemic: Do develop and underdeveloped nations cope alike. Children and Youth Services Review, 119, 105582. https://doi.org/10.1016/j.childyouth.2020.105582

Restaino, M., Vitale, M. P., \& Primerano, I. (2020). Analysing International Student Mobility Flows in Higher Education: A Comparative Study on European Countries. Social Indicators Research, 149(3), 947-965. https://doi.org/10.1007/s11205020-02282-2

Sandhu, P., \& de Wolf, M. (2020). The impact of COVID-19 on the undergraduate medical curriculum. Medical Education Online, 25(1), 1764740. https://doi.org/10.1080/10872981.2020.1764740

Sheeja, N. K., Mathew K., S., \& Cherukodan, S. (2018). Impact of scholarly output on university ranking. Global Knowledge, Memory and Communication, 67(3), 154-165. https://doi.org/10.1108/GKMC-11-2017-0087

UNESCO UIS. (2020). Global Flow of Tertiary-Level Students. http://uis.unesco.org/en/uis-student-flow

Wen, W., \& Hu, D. (2019). The Emergence of a Regional Education Hub: Rationales of International Students' Choice of China as the Study Destination. Journal of Studies in International Education, 23(3), $303-325$. https://doi.org/10.1177/1028315318797154

Wilcha, R.-J. (2020). Effectiveness of Virtual Medical Teaching During the COVID-19 Crisis: Systematic Review. JMIR Medical Education, 6(2), e20963. https://doi.org/10.2196/20963

Yang, P. (2020). China in the global field of international student mobility: An analysis of economic, human and symbolic capitals. Compare: A Journal of Comparative and International Education, $0(0), \quad 1-19$. https://doi.org/10.1080/03057925.2020.1764334 
Supplement

Table S1. Technical component of e-learning as a percentage of all participants.

\begin{tabular}{|c|c|c|c|c|c|c|c|c|c|c|}
\hline \multirow{3}{*}{ Statement } & \multicolumn{10}{|c|}{ Level of Agreement } \\
\hline & \multicolumn{2}{|c|}{ Strongly disagree } & \multicolumn{2}{|c|}{ Disagree } & \multicolumn{2}{|c|}{ Neutral } & \multicolumn{2}{|c|}{ Agree } & \multicolumn{2}{|c|}{ Strongly agree } \\
\hline & No & $\%$ & No & $\%$ & No & $\%$ & No & $\%$ & No & $\%$ \\
\hline The information in the course was easily understood & 67 & 16.46 & 74 & 18.18 & 116 & 28.50 & 85 & 20.88 & 64 & 15.72 \\
\hline The images and texts used were clear and explicit & 58 & 14.25 & 68 & 16.71 & 103 & 25.31 & 94 & 23.10 & 84 & 20.64 \\
\hline The sounds in the e-learning course were clearly audible & 68 & 16.71 & 88 & 21.62 & 100 & 24.57 & 75 & 18.43 & 76 & 18.67 \\
\hline $\begin{array}{l}\text { The videos used helped explain the clinical examination } \\
\text { procedure }\end{array}$ & 77 & 18.92 & 70 & 17.20 & 104 & 25.55 & 78 & 19.16 & 78 & 19.16 \\
\hline The used videos helped me understand the material & 74 & 18.18 & 65 & 15.97 & 98 & 24.08 & 79 & 19.41 & 91 & 22.36 \\
\hline The eLearning method used was user-friendly & 69 & 16.95 & 68 & 16.71 & 104 & 25.55 & 89 & 21.87 & 77 & 18.92 \\
\hline
\end{tabular}


Table S2. Content component of e-learning as a percentage of all participants

\begin{tabular}{|c|c|c|c|c|c|c|c|c|c|c|}
\hline \multirow{3}{*}{ Statement } & \multicolumn{10}{|c|}{ Level of Agreement } \\
\hline & \multicolumn{2}{|c|}{ Strongly disagree } & \multicolumn{2}{|c|}{ Disagree } & \multicolumn{2}{|c|}{ Neutral } & \multicolumn{2}{|c|}{ Agree } & \multicolumn{2}{|c|}{ Strongly agree } \\
\hline & No & $\%$ & No & $\%$ & No & $\%$ & No & $\%$ & No & $\%$ \\
\hline The images and texts used were helpful & 68 & 16.71 & 64 & 15.72 & 116 & 28.50 & 85 & 20.88 & 64 & 15.72 \\
\hline Each topic was adequately discussed & 69 & 16.95 & 88 & 21.62 & 103 & 25.31 & 94 & 23.10 & 84 & 20.64 \\
\hline The discussed topics covered the intended material & 71 & 17.44 & 73 & 17.94 & 100 & 24.57 & 75 & 18.43 & 76 & 18.67 \\
\hline $\begin{array}{l}\text { There were enough scenarios and clinical oriented } \\
\text { discussions }\end{array}$ & 83 & 20.39 & 78 & 19.16 & 104 & 25.55 & 78 & 19.16 & 78 & 19.16 \\
\hline $\begin{array}{l}\text { The case studies and scenarios help you gain a clearer } \\
\text { understanding of the content }\end{array}$ & 85 & 20.88 & 74 & 18.18 & 98 & 24.08 & 79 & 19.41 & 91 & 22.36 \\
\hline There were enough assignments, quizzes, and tests & 62 & 15.23 & 68 & 16.71 & 104 & 25.55 & 89 & 21.87 & 77 & 18.92 \\
\hline The assignments, quizzes, and tests were relevant & 67 & 16.46 & 80 & 19.66 & & & & & & \\
\hline The assignments helped me gaining more knowledge & 72 & 17.69 & 63 & 15.48 & 91 & 22.36 & 101 & 24.82 & 83 & 20.39 \\
\hline $\begin{array}{l}\text { The amount of audio used in the teaching was adequate and } \\
\text { clear }\end{array}$ & 67 & 16.46 & 81 & 19.90 & 107 & 26.29 & 76 & 18.67 & 67 & 16.46 \\
\hline
\end{tabular}


Table 3. General attitude towards e-learning as a percentage of all participants.

\begin{tabular}{|c|c|c|c|c|c|c|c|c|c|c|}
\hline \multirow{3}{*}{ Statement } & \multicolumn{10}{|c|}{ Level of Agreement } \\
\hline & \multicolumn{2}{|c|}{ Strongly disagree } & \multicolumn{2}{|c|}{ Disagree } & \multicolumn{2}{|c|}{ Neutral } & \multicolumn{2}{|c|}{ Agree } & \multicolumn{2}{|c|}{ Strongly agree } \\
\hline & No & $\%$ & No & $\%$ & No & $\%$ & No & $\%$ & No & $\%$ \\
\hline The images and texts used were helpful & 68 & 16.71 & 64 & 15.72 & 116 & 28.50 & 85 & 20.88 & 64 & 15.72 \\
\hline Each topic was adequately discussed & 69 & 16.95 & 88 & 21.62 & 103 & 25.31 & 94 & 23.10 & 84 & 20.64 \\
\hline The discussed topics covered the intended material & 71 & 17.44 & 73 & 17.94 & 100 & 24.57 & 75 & 18.43 & 76 & 18.67 \\
\hline $\begin{array}{l}\text { There were enough scenarios and clinical oriented } \\
\text { discussions }\end{array}$ & 83 & 20.39 & 78 & 19.16 & 104 & 25.55 & 78 & 19.16 & 78 & 19.16 \\
\hline $\begin{array}{l}\text { The case studies and scenarios help you gain a clearer } \\
\text { understanding of the content }\end{array}$ & 85 & 20.88 & 74 & 18.18 & 98 & 24.08 & 79 & 19.41 & 91 & 22.36 \\
\hline There were enough assignments, quizzes, and tests & 62 & 15.23 & 68 & 16.71 & 104 & 25.55 & 89 & 21.87 & 77 & 18.92 \\
\hline The assignments, quizzes, and tests were relevant & 67 & 16.46 & 80 & 19.66 & & & & & & \\
\hline The assignments helped me gaining more knowledge & 72 & 17.69 & 63 & 15.48 & 91 & 22.36 & 101 & 24.82 & 83 & 20.39 \\
\hline $\begin{array}{l}\text { The amount of audio used in the teaching was adequate and } \\
\text { clear }\end{array}$ & 67 & 16.46 & 81 & 19.90 & 107 & 26.29 & 76 & 18.67 & 67 & 16.46 \\
\hline
\end{tabular}


Table S4. Trend for each question and domain

\begin{tabular}{|c|c|c|c|c|c|c|}
\hline & \multicolumn{2}{|c|}{$\begin{array}{l}\text { Negative or rather } \\
\text { Negative }\end{array}$} & \multirow{2}{*}{$\begin{array}{c}\text { Neutral } \\
\text { No }\end{array}$} & \multirow[b]{2}{*}{$\%$} & \multicolumn{2}{|c|}{$\begin{array}{l}\text { Positive or rather } \\
\text { Positive }\end{array}$} \\
\hline & No & $\%$ & & & No & $\%$ \\
\hline \multicolumn{7}{|l|}{ Technical Aspect } \\
\hline $\begin{array}{l}\text { The information in the course was } \\
\text { easily understood }\end{array}$ & 141.00 & 34.64 & 116 & 28.50 & 149.00 & 36.61 \\
\hline $\begin{array}{l}\text { The images and texts used were clear } \\
\text { and explicit }\end{array}$ & 126.00 & 30.96 & 103 & 25.31 & 178.00 & 43.73 \\
\hline $\begin{array}{l}\text { The sounds in the e learning course } \\
\text { were clearly audible }\end{array}$ & 156.00 & 38.33 & 100 & 24.57 & 151.00 & 37.10 \\
\hline $\begin{array}{l}\text { The videos used helped explain the } \\
\text { clinical examination procedure }\end{array}$ & 147.00 & 36.12 & 104 & 25.55 & 156.00 & 38.33 \\
\hline $\begin{array}{l}\text { The used videos helped me } \\
\text { understand the material }\end{array}$ & 139.00 & 34.15 & 98 & 24.08 & 170.00 & 41.77 \\
\hline $\begin{array}{l}\text { The eLearning method used was user- } \\
\text { friendly }\end{array}$ & 137.00 & 33.66 & 104 & 25.55 & 166.00 & 40.79 \\
\hline \multicolumn{7}{|l|}{ Content Aspect } \\
\hline $\begin{array}{l}\text { The images and texts used were } \\
\text { helpful }\end{array}$ & 132.00 & 32.43 & 91 & 22.36 & 184.00 & 45.21 \\
\hline Each topic was adequately discussed & 157.00 & 38.57 & 107 & 26.29 & 143.00 & 35.14 \\
\hline $\begin{array}{l}\text { The discussed topics covered the } \\
\text { intended material }\end{array}$ & 144.00 & 35.38 & 102 & 25.06 & 161.00 & 39.56 \\
\hline $\begin{array}{l}\text { There were enough scenarios and } \\
\text { clinical oriented discussions }\end{array}$ & 161.00 & 39.56 & 117 & 28.75 & 129.00 & 31.70 \\
\hline $\begin{array}{l}\text { The case studies and scenarios help } \\
\text { you gain a clearer understanding of } \\
\text { the content }\end{array}$ & 159.00 & 39.07 & 111 & 27.27 & 137.00 & 33.66 \\
\hline $\begin{array}{l}\text { There were enough assignments, } \\
\text { quizzes, and tests }\end{array}$ & 130.00 & 31.94 & 107 & 26.29 & 170.00 & 41.77 \\
\hline $\begin{array}{l}\text { The assignments, quizzes, and tests } \\
\text { were relevant }\end{array}$ & 147.00 & 36.12 & 106 & 26.04 & 154.00 & 37.84 \\
\hline $\begin{array}{l}\text { The assignments helped me gaining } \\
\text { more knowledge }\end{array}$ & 135.00 & 33.17 & 121 & 29.73 & 151.00 & 37.10 \\
\hline $\begin{array}{l}\text { The amount of audio used in the } \\
\text { teaching was adequate and clear }\end{array}$ & 148.00 & 36.36 & 95 & 23.34 & 164.00 & 40.29 \\
\hline \multicolumn{7}{|l|}{ Attitude Aspect } \\
\hline $\begin{array}{l}\text { I feel confident to apply my } \\
\text { eLearning knowledge to patients }\end{array}$ & 170.00 & 41.77 & 102 & 25.06 & 138.00 & 33.91 \\
\hline I enjoy the eLearning experience & 154.00 & 37.84 & 107 & 26.29 & 149.00 & 36.61 \\
\hline $\begin{array}{l}\text { I studied regularly and adequately as } \\
\text { much as before the pandemic }\end{array}$ & 148.00 & 36.36 & 94 & 23.10 & 168.00 & 41.28 \\
\hline $\begin{array}{l}\text { I felt the urge to study as much as } \\
\text { before the pandemic }\end{array}$ & 135.00 & 33.17 & 98 & 24.08 & 177.00 & 43.49 \\
\hline $\begin{array}{l}\text { I am comfortable with the knowledge } \\
\text { I gained }\end{array}$ & 162.00 & 39.80 & 100 & 24.57 & 148.00 & 36.36 \\
\hline $\begin{array}{l}\text { I believe that multimedia can } \\
\text { substitute some direct teaching }\end{array}$ & 153.00 & 37.59 & 123 & 30.22 & 134.00 & 32.92 \\
\hline $\begin{array}{l}\text { Adding eLearning to future teaching } \\
\text { and rotations will be beneficial }\end{array}$ & 139.00 & 34.15 & 124 & 30.47 & 147.00 & 36.12 \\
\hline I believe that eLearning can save time & 153.00 & 37.59 & 114 & 28.01 & 143.00 & 35.14 \\
\hline $\begin{array}{l}\text { I believe that this experience was } \\
\text { beneficial }\end{array}$ & 162.00 & 39.80 & 107 & 26.29 & 141.00 & 34.64 \\
\hline $\begin{array}{l}\text { I am willing to try further eLearning } \\
\text { teaching }\end{array}$ & 158.00 & 38.82 & 112 & 27.52 & 140.00 & 34.40 \\
\hline
\end{tabular}

